\title{
Primórdios de um professor. Os primeiros cursos de Ricardo Benzaquen de Araújo na PUC-Rio.
}

\author{
Maria Laura Viveiros de Castro Cavalcanti* \\ Programa de Pós-Graduação em Sociologia e Antropologia / IFCS / UFRJ
}

Conheci Ricardo no primeiro semestre de 1974 como monitor de minha turma de História Moderna I na PUC-Rio. Vinda do curso de Desenho Industrial, eu ingressara no curso de História no segundo semestre de 1973. Ricardo vinha da Sociologia, concluiria seu curso de História no final de 1974, e já no ano seguinte começaria a lecionar regularmente as disciplinas de História Antiga e Medieval como professor do Departamento de História da PUC. Eu me formei no final de 1976 e, assim, entre 1974 e 1976 pude testemunhar como aluna a transformação de meu monitor, que a essa altura já era meu amigo, em um jovem e estimulante professor. É sobre isso que quero falar, pois esses cursos revelam toda a amplitude e mesmo ousadia de interesses e o profundo e atualizado conhecimento bibliográfico de Ricardo que inovava, com seus cursos tão marcantes, a própria forma de ensino de História que se adotava até então e mesmo a concepção do que até então se entendia por História.

Aqueles eram ainda os anos de chumbo. No início da administração Geisel a ditadura iniciava um certo abrandamento, mas as prisões de estudantes ainda ocorriam, o movimento estudantil estava banido, as histórias de prisões e torturas corriam entre nós a boca pequena - eu tinha experiências na minha própria família - e o medo de delações fazia parte de nosso cotidiano. Sabíamos geralmente identificar quem eram os policiais infiltrados nos cursos, que buscavam em vão aproximações. Mesmo a realização de grupos de estudo nos preocupava e era cercada de cuidados. Nesse contexto, as leituras marxistas (extraclasses e por vezes intraclasses também) eram o credo obrigatório de todo estudante que quisesse integrar

\footnotetext{
* Maria Laura Viveiros de Castro Cavalcanti é professora e pesquisadora do Programa de Pósgraduação em Sociologia e Antropologia (PPGSA) do Instituto de Filosofia e Ciências Sociais (IFCS) da Universidade Federal do Rio de Janeiro (UFRJ).

E-mail: contato@lauracavalcanti.com.br
} 
a oposição à ditadura e, no segundo semestre de 1973, recém chegada ao curso, já me vi tendo às mãos os livros de introdução ao materialismo histórico de Marta Harnecker e dos demais autores que se seguiam a essa iniciação (Louis Althusser, Nikos Poulantzas, entre outros).

O prédio da ala Frings da PUC abrigava o departamento de História e a maior parte das disciplinas do curso. As cadeiras de Filosofia, Letras, Pedagogia que eventualmente cursávamos eram no prédio Cardeal Leme. Uma parte do curso era um tanto antiquada com professores que seguiam visões mais fatuais ou mesmo uma história centrada em personalidades. ${ }^{1}$ Mas lá estavam também Francisco Calazans Falcon, que ministrava as cadeiras de História Moderna e Contemporânea, e Ilmar Rholloff de Mattos, responsável por parte das cadeiras de História do Brasil. Eles integravam a ala intelectual mais contemporânea do curso, traziam uma visão mais ampla e arejada dos assuntos abordados e uma bibliografia atualizada. Ricardo era monitor das disciplinas de Falcon. ${ }^{2}$

Ricardo, logo Ricardinho, a quem logo depois de uma das primeiras aulas de História Moderna I, no primeiro semestre de 1974, encontrei num cafezinho no bar no subsolo dos Pilotis que dava para a pequena rua da então Vila dos Diretórios que aos poucos reiniciavam sua movimentação. Não me lembro exatamente do que nos dissemos, apenas da prosa fácil, fluente, que trouxe o sentimento imediato de um encontro verdadeiro. Nossa amizade nasceu ali, e aquela conversa tão acolhedora, despretensiosa e estimulante prolongou-se através dos anos e só se interrompeu com a internação de Ricardo no final de 2016. Poucos meses antes dessa internação, no final de julho de 2016, quando estava no aeroporto de Nova Iorque voltando para o Rio, recebi o telefonema em que ele me contou do diagnóstico desfavorável que lhe dera o médico. Com seu fino senso de humor, retrucara ao ouvir o prognóstico de um ano de vida: "Mas só isso?" Não pretendia desistir tão facilmente; afinal, estava habituado a driblar, disse-me ele, a indesejada das gentes desde há muito "pelo menos desde os tempos da Var Palmares!".

\footnotetext{
1 Vale dizer que nem todos que considerávamos "antiquados" o eram de fato. Lembro especialmente o Prof. Arthur Cézar Ferreira Reis, professor de História das Américas, um americanista muito interessante, especialista na história da Amazônia, que nos abria sua biblioteca particular, instalada em seu apartamento, na Rua Cesário Alvim, no Humaitá, para nossos estudos e seminários.

${ }^{2} \mathrm{O}$ grupo de colegas era muito estimulante e algumas amizades duradouras se estabeleceram com Angela Loureiro, Maria Luiza Heilborn, Maria Helena Castro, Maria Alice Rezende de Carvalho, Marco Antônio Pamplona, Eduardo Schnoor, e Ovídio de Abreu Filho que viria a ser pai de minhas duas filhas, Joana e Maria Clara.
} 
Creio que se referia também não apenas ao seu sempre instável quadro de saúde, mas a sua recuperação diante da tristeza da perda súbita em setembro de 2005 de Silvana Miceli de Araújo, sua esposa e mãe das gêmeas Alice e Carolina, nascidas em 25 de março de 1980 (quando já éramos todos contemporâneos na pós-graduação em Antropologia Social do Museu Nacional). E também à sua superação da perda de sua mãe, sempre muito próxima dele, Dona Sol, em 2008. ${ }^{3}$

Em 1974, Silvana cursava Sociologia e Ricardo já a namorava. Ele já era então o Ricardo de quem sempre me lembrarei: discreto e envolvente, bem branquinho, com os olhos castanhos miúdos que olhavam de fato com quem falava, com sua barba e cabelos sempre um tanto despenteados, gordinho e muito ágil física e intelectualmente, gaguejava um pouco e ofegava sempre no correr das aulas que proferia substituindo o professor. No ano seguinte, Ricardo tornou-se professor do Departamento de História e fui sua aluna em três disciplinas: "Fundamentos de História Antiga e Medieval", em 1975.01; "História Medieval" em 1975.02; "História Antiga", em 1976.02.

Em "Fundamentos de História Antiga e Medieval", uma das primeiras leituras foi A cidade Antiga, de Fustel de Coulanges (1975 [1864]) que acabava de ser traduzido para o português. Ricardo organizou uma lista dos interessados em comprar o livro, encomendou os exemplares a D. Vana na Livraria Leonardo Da Vinci, na Avenida Rio Branco, que ele frequentava regularmente aos sábados de manhã; foi buscá-los e trouxe-os para a sala de aula! Queria que lêssemos aquela maravilha. Guardo até hoje o exemplar sublinhado e anotado a lápis com alguns de seus comentários e explicações. A primeira anotação na folha de rosto diz "autor incorporado à tradição da história e da antropologia, onde permanece mais vivo". Na leitura que meu jovem professor nos propunha: "em vez de opor economia e religião iríamos tentar descobrir o que ele, Fustel de Coulanges, está entendendo

\footnotetext{
${ }^{3}$ Ricardo era filho único de pais amazonenses. O pai nascera em Manaus e Dona Sol, como a chamávamos, era natural de Parintins, onde passou a infância e a juventude. Entrevistei-a certa feita por conta de minha pesquisa sobre o Bumbá de Parintins. O pai de Dona Sol era comerciante de ascendência judaica sefaradin, tinha comércio em Parintins, tendo depois se estabelecido em Manaus. Jovem ainda ela era seu braço direito e encarregada das contas. O bisavô materno de Ricardo era regatão na Amazônia, percorrendo com sua embarcação os rios e igarapés até os mais distantes rincões da região. De tal modo que cada um de seus filhos nascera em um país diferente. O avô de Ricardo, no Brasil. Dona Sol me disse que Ricardo se parecia demais com um de seus tios-avôs, que amava os livros e os estudos. O pai de Ricardo trabalhava numa empresa de seguros tendo sido deslocado para o Rio de Janeiro quando Ricardo era ainda criança. Foram morar em Copacabana, onde Dona Sol, antes de se estabelecer como contadora, era doceira.
} 
por religião em uma abordagem não moralizante"; "mesmo que associado a um esquema evolucionista (numa linha evolutiva não mundial, mas só ocidental) ele está pensando somente a civilização ocidental" e quer revelar "regras e uma maneira de operar particulares", que, como nos diz o próprio Fustel de Coulanges, "jamais voltarão a reger a humanidade" (p. 7). A morte e o culto aos mortos ligando o visível ao invisível; a importância dos ritos a vincularem os grupos sociais; a autoridade como uma construção social; o fogo como símbolo sagrado da religião doméstica; o culto que buscava apagar a diferença entre as gerações articuladas num princípio comum através das linhagens; a religião, enfim, como o grande articulador das regras sociais, da transmissão dos diretos de herança, da vida política da cidade, da economia, da guerra e da paz. A Roma antiga nunca fora tão diferente e ao mesmo tempo tão acessível a meus olhos encantados com aquela nova possibilidade de compreensão de um passado tão distante. ${ }^{4}$

Em 1976.02, cursei com Ricardo como professor a disciplina "História Antiga". Ricardo era muito amigo de Théo Santiago - que havia sido monitor junto com ele. Théo participava da coordenação da Coleção Ciências Sociais ${ }^{5}$ da Editora Francisco Alves que publicou naquele mesmo ano a tradução dos três volumes da série organizada por Jacques Le Goff e Pierre Nora História: novos problemas; História novas abordagens; História: novos objetos. A série tinha sido publicada na França, pela Gallimard em 1974 e sua tradução integrou nosso curso. Lembro-me bem da leitura do volume História: novos objetos. Tenho no sumário assinalados os artigos que me competiram trabalhar: "Os jovens: o cru, a criança grega e o cozido" de Pierre Vidal-Naquet (1974, p. 116-133) e "O mito: Orfeu no mel" de Marcel Detienne (1974, p.52-67). Surpreendo-me hoje vendo anotadas nas margens da página 123 do artigo de Vidal-Naquet as referências a Arnold Van Gennep, ressaltando o tempo e o espaço próprios dos ritos de passagem. $E$ as discussões de Edmund Leach acerca dos disfarces e inversões rituais! $\mathrm{O}$ artigo de Detienne foi objeto de um trabalho de curso que infelizmente não guardei. Em suas páginas vejo anotado "não se trata da atribuição de valores mas da relação entre Natureza e Cultura"; "o casamento como

\footnotetext{
${ }^{4}$ Muitos anos depois, já no mestrado, eu voltaria a ter encantamento semelhante com a leitura de As formas elementares da vida religiosa, de Émile Durkheim, que trazia essa mesma amplitude de horizontes para a compreensão da religião dos povos ditos primitivos. E aquela abordagem me soava muito familiar.

${ }^{5}$ Os outros coordenadores eram Roberto Oswaldo Cruz, Ana Maria de Castro e Alba Zaluar Guimarães.
} 
efetuando a passagem da natureza para a cultura no tempo lógico e não cronológico do mito" (p.52). O texto se inicia com a discussão dos estudos da mitologia em antropologia, discussão que por sinal Detienne conhece como poucos e resultou em seu belíssimo livro $A$ invenção da mitologia (1992) [primeira edição francesa de 1981]. Détienne falava do "contexto etnográfico", que revelava a "estreita relação entre a conduta das abelhas e o comportamento sexual do apicultor" e conduzia ao encontro de Aristeu e de Eurídice (p. 56). Tudo era perturbadoramente inovador. Como era possível que um mito sintetizasse e abrigasse tamanho conjunto de relações e sentidos insuspeitos? Não é à toa que poucos anos depois, já no Museu Nacional, num curso de Roberto DaMatta, vi redespertar, com um exercício de análise estrutural do conto "João mais Maria" em uma versão coletada por Sílvio Romero, o amor pelo estudo dos mitos que, como os sonhos, se desdobram em múltiplos sentidos quanto mais interrogados.

Entre esses dois cursos, houve também o decisivo curso de História Medieval no segundo semestre de 1975: leríamos A feiticeira de Jules Michelet e A inquisição e os cristãos novos em Portugal de Antônio José Saraiva. Os livros foram como de praxe encomendados por ele para os alunos interessados em tê-los. O livro de Michelet acabara de ser editado pelo Círculo do Livro em 1974 e me surpreendeu, pois sua capa dura e rosa-shocking trazia uma bela imagem psicodélica em que se misturavam contra o fundo azul de uma noite escura nuvens, um fiapo de lua, duas estrelas e o rosto de uma mulher com três olhos azuis que nos fitavam bem abertos, emoldurados por muitos fios de cabelos rosados como que soltos ao vento. E assunto era dos demônios! "Dessa forma, o cristianismo penetrou pelo solitário caminho do celibato, combatido em vão pelas leis dos imperadores, e acabou lançando-se à vida monástica. Mas o homem estava sozinho no deserto? Não. O demônio o acompanhava, com todas as suas tentações" (p. 22). E feminista!: "Singelo e comovedor começo das religiões e das ciências. Depois tudo se dividirá; verse-á o homem especial, jogral, astrólogo ou profeta, nigromante, sacerdote, médico. Mas a princípio a mulher é tudo" (p.5).

Aquela escrita exuberante, semi-ficcionalizada, cheia de fortes imagens e de juízos era mesmo a de um historiador? Ricardo nos assegurava que sim. Não se tratava apenas de lançar nova luz sobre a transição da Idade Média para o Renascimento através de um tema obscuro e inusitado. A história narrada era claramente interpretada e o contato com aquela escrita tão inventiva dentro de uma disciplina acadêmica era também uma novidade absoluta que desorganizava esquemas mentais preconcebidos. 
Da Feiticeira, fomos direto para a Inquisição e os cristãos novos, de José Saraiva. Quando abro agora o livro acho um bilhete com a letra de Ricardo com uma indicação bibliográfica: "'Uma longa guerra social. Os retornos da repressão inquisitorial em Portugal', José Veiga Torres. IN Revista de História Econômica e Social, Lisboa, Sá da Costa, 1978, n. 1." Creio que Ricardo me indicou essa leitura para ajudar a relativizar a ideia de Saraiva de que aquele passado da inquisição portuguesa fora encerrado para sempre. Saraiva era mais moderno, ordenado, seu em estilo assumidamente polêmico e igualmente fascinante e convincente: "Nosso propósito, nas páginas seguintes, é problematizar a Inquisição, problematizando do mesmo passo o conceito de Cristãos-novos. Na copiosa literatura publicada sobre ambos os temas raramente se ouvem as perguntas: O que é a Inquisição? O que são os Cristãos- novos? Dão-se os problemas como previamente resolvidos. Pôr a pergunta e propor uma resposta - tal é a nossa intenção" (p. 12). Uma época distante revivia através de uma pesquisa notável que, ao fornecer respostas muito fundamentadas, abria também o conhecimento para a possibilidade de mais perguntas com outras respostas possíveis.

Minha amizade com Ricardo foi a de uma vida cheia de muitos encontros, de deliciosas conversas e muitos livros, e mútuas dívidas de gratidão. Mas essa já é outra história e quis aqui apenas registrar o tanto que aprendi com meu jovem professor. Naqueles anos 1970, sem alarde, ousada e muito livremente, Ricardo Benzaquen de Araújo abria e explorava para si e para nós, com imenso prazer, horizontes intelectuais inteiramente novos.

\section{REFERÊNCIAS}

DETIENNE, Marcel.

(1992). A invenção da mitologia. Rio de Janeiro/

Brasília: José Olympio Editora/Ed. Unb.

COULANGES, Fustel de; DENIS, Numa.

(1975). A cidade antiga. São Paulo: Livraria Editora Hemus.

LE GOFF, Jacques; NORA, Pierre.

(1976). História: Novos Objetos. Rio de Janeiro: Livraria Francisco Alves Editora.

LE GOFF, Jacques; NORA, Pierre.

(1976). História: Novas Abordagens. Rio de Janeiro: Livraria Francisco Alves Editora.
LE GOFF, Jacques; NORA, Pierre.

(1976). História: Novos Problemas. Rio de Janeiro: Livraria Francisco Alves Editora.

MICHELET, Jules.

(1974). A FEITICEIRA. São Paulo: Círculo do Livro.

SARAIVA, Antônio José.

(1969). Inquisição e cristão-novos. Coleção Civilização Portuguesa. Porto: Editorial Nova Limitada.

\section{Recebido em}

março de 2017

\section{Aprovado em}

maio de 2017 